\title{
PAPILLARY PINEOCYTOMA IN CHILD: A CASE REPORT
}

\author{
Wiesław Marcolab*, Katarzyna Kotulska ${ }^{\mathrm{a}}$, Wiesława Grajkowska ${ }^{\mathrm{c}}$, Dariusz Gołkad, \\ Paweł Właszczuk ${ }^{\mathrm{d}}$, Monika Drogosiewicz ${ }^{\mathrm{e}}$, Marek Mandera ${ }^{\mathrm{b}}$, Joanna Lewin-Kowalik ${ }^{\mathrm{a}}$, \\ Marcin Roszkowski ${ }^{\mathrm{f}}$
}

a Department of Physiology, Medical University of Silesia, Katowice, Poland

${ }^{b}$ Division of Neurosurgery, Department of Pediatric Surgery, Medical University of Silesia, Katowice, Poland

c Department of Pathology, The Children's Memorial Health Institute, Warsaw, Poland

d Department of Pathology, Medical University of Silesia, Katowice, Poland

e Department of Oncology, The Children's Memorial Health Institute, Warsaw, Poland

$f$ Department of Neurosurgery, The Children's Memorial Health Institute, Warsaw, Poland

*e-mail:Vie@alpha.net.pl

Received: February 20, 2007; Accepted (with revision): May 28, 2007

Key words: Pineal tumors/Pineocytoma/Papillary structures/Prognosis/Therapy/

Background: Papillary pineocytoma is an extremely rare tumor usually with a poor outcome.

Case report: We report a case of a 10-year-old-girl with pineal gland tumor and obstructuve hydrocephalus diangnosed using MRI. The child was successful treated by insertion of a ventriculoperitoneal shunt and consecutive tumor resection by supracerebellar-infratentorial approach. Histopathological examination showed a papillary structure of the pineocytoma. As such, tumors are considered to be aggressive the child was subjected to radio- and chemotherapy.

Conclusion: At six year follow-up after surgery, the patient is symptom-free and the MRI shows no tumor recurrence.

\section{INTRODUCTION}

Pineal neoplasms are uncommon and therefore little is known about their biology and clinical behavior. Among these tumors, papillary pineocytoma appears to be especially rare. Since the first description given by Trojanowski et al., only a few other cases have been reported ${ }^{4-5}$. The data on prognosis in the case of these tumors are also conflicting $^{1-2,4-9}$. Here, we present the clinical and histopathological description of papillary pineocytoma in a child with favorable outcome.

\section{CASE REPORT}

Ten-year-old girl presented with gradually increasing headaches and vomiting since August 1998. A CT scan demonstrated hydrocephalus and pineal region tumor. A ventriculoperitoneal shunt was inserted and the child was referred to the Oncology Department. Tumor markers (alpha-fetoprotein and human chorionic gonadotropin) appeared to be negative. No neoplastic cells were detected in the CSF. Magnetic resonance imaging (MRI) performed two months after veniculoperitoneal
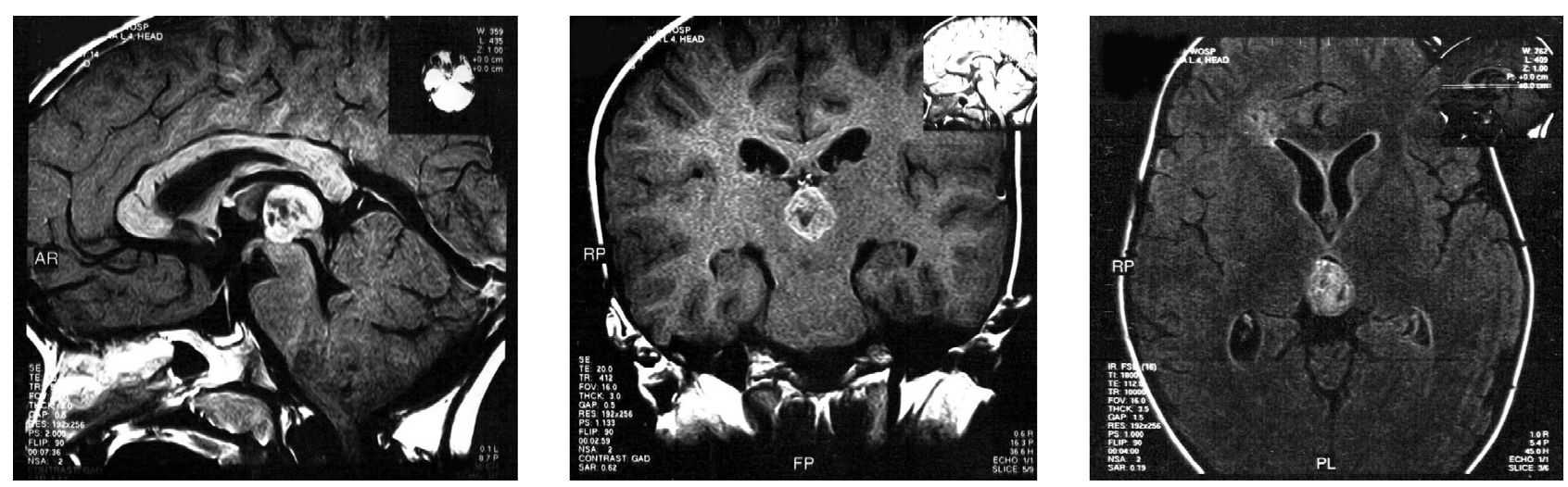

Fig. 1. MR sagitall (A), axial (B) and coronal (C) images demonstrating the pineal region tumor. 

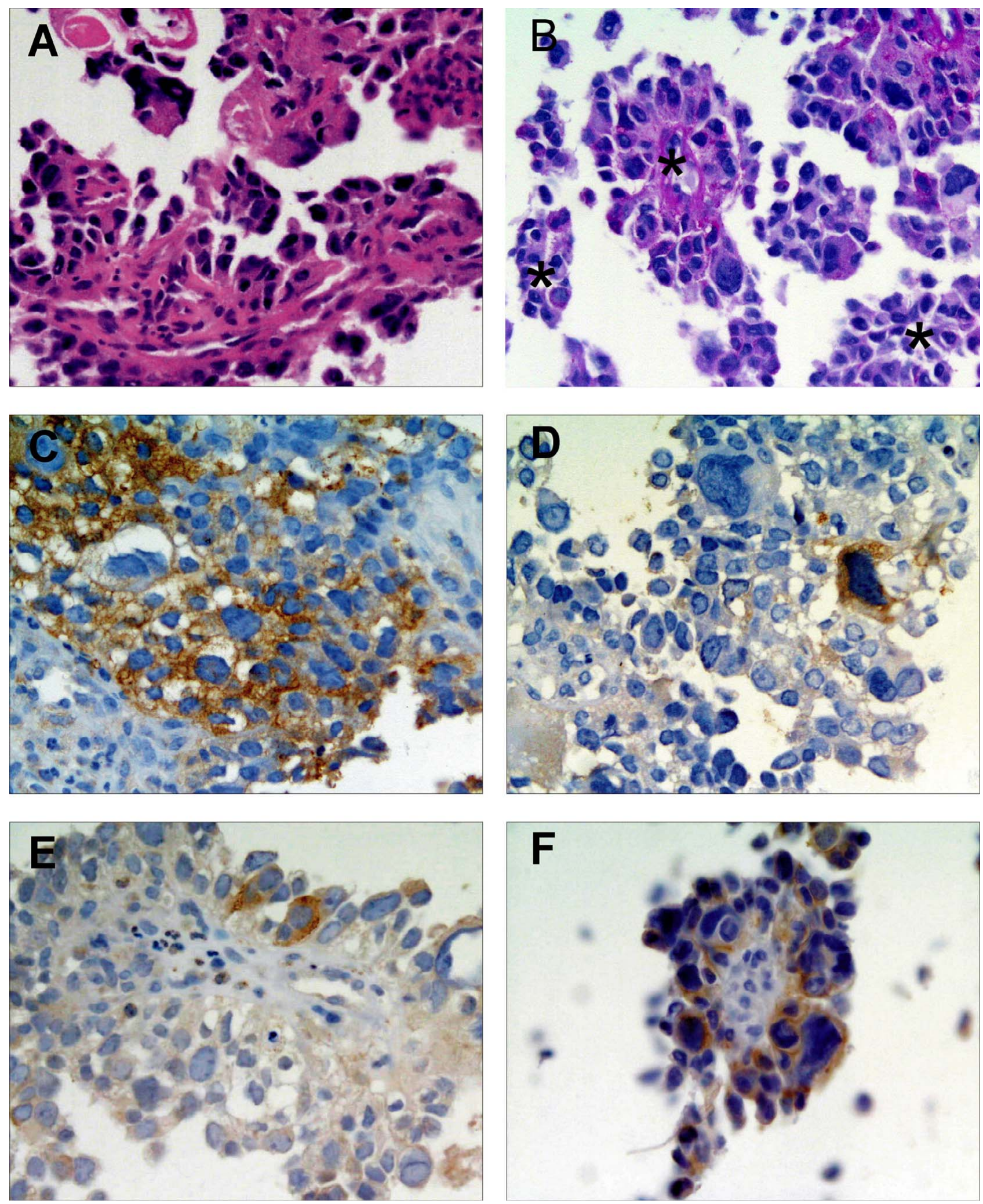

Fig. 2. Microscopic appearance of the papillary pineocytoma. A - tumor presenting a papillary structures in HE staining. B - PAS reaction residually positive. Rosettes are marked by asterisks. In C, D, E, and F positive immunohistochemical staining for: NSE, S-100, Synaptophysin and CK, respectively. Paraffin block. 
shunt revealed a giant pineal region tumor (Fig. 1). No hydrocephalus was found on MRI. In November 1998, the child underwent gross total tumor microsurgical resection by a supracerebellar-infratentorial approach. The pathological examination revealed a neoplasm presenting a papillary structure and resected without stromal tissue (Fig. 2). Rosettes and perivascular pseudorosettes were observed. Cells lining papillary structures were polymorphous, occasionally having extremely atypical, plump nuclei. Prominent, sometimes double, nucleoli were found in some cells. Intranuclear inclusions were also present. The cytoplasm was eosinophyllic, in some cells having a foamy structure with single vacuoles. Connective tissue papillary cores presented with minimal inflammatory infiltrations and wide blood vessel. PAS staining results in most cells were negative. Occasionally, minute PASpositive granules were present. Focally, among cells, PASpositive globules present within the stroma. Mitotic Index (MI) was 10/10 HPF (high power fields) with abnormal mitoses present. Immunohistochemical examination was also performed and showed positive membrane-, and cytoplasmatic reaction for $\mathrm{CK}$ (cytokeratin) and for synaptophysin in some cells, moderate to strong positive reaction for S-100 in many large and small cells. GFAP, NF, bcl-2, bax as well as p53 staining was negative. Strong positive reaction for NSE was seen in the majority of cells. On the basis of these examinations, a diagnosis of papillary pineocytoma was established and the child was subjected to radiotherapy and chemotherapy. In April 2000 she completed the treatment protocol. Currently, six years after surgery, she is symptom-free and follow-up MRI shows no tumor recurrence.

\section{DISCUSSION}

Although pineocytomas usually have a good prognosis, papillary pineocytoma seemed to be an exception. Papillary pineocytoma exhibits immunohistochemical features characteristic for pineocytoma, as reactivity for $\mathrm{CK}$, synaptophysin, NSE and S-100 ${ }^{1,2}$. Like other pineocytomas, the reported tumor was negative for GFAP and NF. A papillary pattern is usually considered to indicate malignancy of the tumor ${ }^{2,3,9-10}$. The majority of papillary pineocytomas reported in the literature showed recurrences or dissemination within the CNS. However, good response to treatment and no recurrence at six years follow-up were found in the presented patient.

Thus may suggest that papillary pineocytoma in children has a more favourable outcome than in adults. Negative staining for antiapoptotic agent, bcl-2, also sup- ports the benign character of the tumor. On the other hand, the patient postoperatively received aggressive adjuvant treatment, which could have reversed a bad prognosis. Adjuvant therapy is not a standard procedure in pineal region tumors, and in this particular case was introduced because of the papillary structure of the tumor, indicating high malignancy. Negative staining for antiapoptotic agent, bcl-2, also confirmed the benign character of the tumor. The best of our knowledge, the reported case is the first description of papillary pineocytoma in childhood. It is not known whether such tumors in children share the same clinical and morphological features as papillary pineocytomas in adults. There are also many controversies concerning optimal therapy in such cases. Therefore, further studies are needed to establish the possible prognostic value of immunological markers and prognosis in papillary pineocytoma.

\section{REFERENCES}

1. Hirato J, Nakazato Y. Pathology of pineal region tumors. J Neurooncol 2001; 54:235-249.

2. Jouvet A, Fauchon F, Liberski P, Saint-Pierre G, Didier-Bazes M, Heitzmann A, Delisle MB, Biassette HA, Vincent S, Mikol J, Streichenberger N, Ahboucha S, Brisson C, Belin MF, FevreMontagne M. Papillary tumor of the pineal region. Am J Surg Pathol 2003; 27:505-512.

3. Perry A, Gutmann DH, Perry A, Gutmann DH, Reifenberger G. Molecular pathogenesis of meningiomas. J Neurooncol 2004; 70:183-202.

4. Trojanowski JQ, Tascos NA, Rorke LB. Malignant pineocytoma with prominent papillary features. Cancer 1982; 50:1789-1793.

5. Vaquero J, Coca S, Martinez R, Escandon J. Papillary pineocytoma. J Neurosurg 1990; 73:135-137.

6. Fevre-Montange M, Hasselblatt M, Figarella-Branger D, Chauveinc L, Champier J, Saint-Pierre G, Taillandier L, Coulon A, Paulus W, Fauchon F, Jouvet A. Prognosis and histopathologic features in papillary tumors of the pineal region: a retrospective multicenter study of 31 cases. J Neuropathol Exp Neurol 2006; 65:1004-1011.

7. Kern M, Robbins P, Lee G, Watson P. Papillary tumor of the pineal region-a new pathological entity. Clin Neuropathol 2006; 25:185192.

8. Shibahara J, Todo T, Morita A, Mori H, Aoki S, Fukayama M. Papillary neuroepithelial tumor of the pineal region. A case report. Acta Neuropathol (Berl) 2004; 108:337-340.

9. Hasselblatt M, Blumcke I, Jeibmann A, Rickert CH, Jouvet A, van de Nes JA, Kuchelmeister K, Brunn A, Fevre-Montange M, Paulus W. Immunohistochemical profile and chromosomal imbalances in papillary tumours of the pineal region. Neuropathol Appl Neurobiol 2006; 32:278-283.

10. Fevre-Montange M, Champier J, Szathmari A, Wierinckx A, Mottolese C, Guyotat J, Figarella-Branger D, Jouvet A, Lachuer J. Microarray analysis reveals differential gene expression patterns in tumors of the pineal region. J Neuropathol Exp Neurol. 2006; 65:675-684. 